\title{
Knowledge management in project environments
}

\author{
C.J. Pretorius and H. Steyn* \\ Department of Engineering and Technology Management \\ Engineering Building No 2, University of Pretoria, Pretoria 2000, Republic of South Africa \\ The first author was, at the time of writing this paper, enrolled on the MSc (Project Management) Programme \\ of the Department of Engineering and Technology Management, University of Pretoria \\ Herman.steyn@up.ac.za
}

Received December 2004

\begin{abstract}
Knowledge management is widely acclaimed to be a source of considerable financial advantage for organisations. Various authors realise that project environments could also benefit from the creation and re-use of knowledge, including from the lessons learned that should be documented during project close-out. Projects face specific challenges (limited time spans, changing and dispersed teams) and the reduction of project risk, time and cost through knowledge management, may well prove worthwhile.
\end{abstract}

\begin{abstract}
This paper reviews the literature on knowledge management, both in organisations in general and in project environments specifically. A framework for knowledge management is derived from literature. The paper also reports on an investigation of knowledge management practices in four cases within a single South African business environment. Knowledge management practices similar to ones reported abroad were found.

A model is proposed for the management of knowledge in project environments, both within a single project (intraproject) and between projects (inter-project) and. guidelines for knowledge management in project environments are provided. It is also suggested that, while the management of explicit knowledge is common in project management, more attention should be given to the sharing of tacit knowledge through human interaction.
\end{abstract}

*To whom all correspondence should be addressed.

\section{Introduction}

\section{Knowledge management in organisations}

The financial benefits produced by creating and sharing knowledge, are widely recognised. The effective utilisation of organisational knowledge is perceived to be essential to 'improve bottom line results' (King, 2001) and to 'create wealth' (Stewart, 2001:11). Another view holds that the new knowledge economy has the potential for 'dramatically increasing economic and social prosperity’ (Allee, 2003:19).

Knowledge management can be defined as the acquisition, creation, packaging or application of knowledge (Davenport, Jarvenpaa \& Beers 1996; Bowman, 2002). This study focuses on the codification and dissemination of knowledge.

Extensive references substantiate that knowledge is more than data and information. Nevis, DiBella and Gould (1995) state that knowledge includes the meaning or interpretation of the information and of intangibles such as the knowledge of experienced people. Another view holds that 'only people can take the information generated by investigative processes and craft that information into knowledge' (Whysall, 2003).
Explicit knowledge can be documented and consists of formal models, rules and procedures, while tacit knowledge consists of implicit, mental models and the experiences of individuals (Spiegler, 2003). Tacit knowledge cannot easily be codified (transformed into documents), but can, in part, be made explicit and can be leveraged through explication and sharing (King, 2001). Tacit knowledge is transferred among individuals working closely together through socialisation processes such as apprenticeships, learnerships and direct observation (Griffith, Swayer \& Neale, 2003). Knowledge can thus be managed through the use of two strategies: codification and personalisation. The codification strategy would focus on codifying knowledge, storing it in a database where it can be accessed and used by anyone in the company. The personalisation strategy would focus on the sharing of knowledge through direct person-to-person contacts (Hansen, Nohria \& Tierney, 1999). Effective knowledge management implies that both these strategies could be used. The interaction between explicit and tacit knowledge is referred to as 'knowledge conversion' (Nonaka, Toyama \& Konno 2001:16). This knowledge conversion consists of different modes identified in the SECI process as: socialisation (tacit to tacit knowledge); externalisation (tacit to explicit knowledge); combination (explicit to explicit knowledge) and internalisation (explicit to tacit knowledge). 
Knowledge transfer happens through communication, directly between people or aided by technology. Although technology is a vehicle for processing and disseminating data (Spiegler, 2003), there seems to be an inverse proportionality between the technology used and the amount of content transferred in a communication (Stewart, 2001:121). Face-to-face conversations (low technology) will convey more content (including facial expressions and voice inflections) than the higher technology option of electronic mail. The communication method should therefore be prescribed by the kind of knowledge transfer required: for the transfer of explicit knowledge higher technology methods such as electronic mail would be suitable, while face-to-face communication would be best for the transfer of tacit knowledge. The choice of technology is also influenced by how knowledge intensive the work is: as work becomes more knowledge intensive, rapid manipulation across distances becomes less important and face-to-face communication more important (Davenport et al., 1996).

According to Nonaka et al. (2001: 24), 'face-to-face interaction is the only way to capture the full range of physical senses and psycho-emotional reactions such as ease or discomfort, which are important elements in sharing tacit knowledge'.

Efficient knowledge sharing can be facilitated by locating people in close proximity to one another (Stewart, 2001:205) and by allowing people the time to get acquainted so that trust can develop between them (Stewart, 2001:239). Processes that could be incorporated to encourage knowledge sharing include: initiation (Stewart, 2001:209); job rotation (Garvin, 1993); and offering compensation and rewards such as promotions (Stata, 1989). Group activities including communities of practice, mentoring and coaching are important for creating, sharing and applying knowledge (Allee, 2003:70).

The culture and values of an organisation (Nevis et al., 1995), as well as the leadership of an organisation, have a significant impact on the learning process (Stata, 1989). According to Garvin (1993) 'Only if top management explicitly frees up employees' time for this purpose, does learning occur with any frequency'. It is also important to create an environment in which an appointed knowledge manager would be responsible to keep the database orderly and index new knowledge with keywords for easy retrieval (Bowman, 2002). Companies that create an environment of trust with strong social connections and knowledge sharing are finding their culture to be a source of real competitive advantage (Allee, 2003:129).

\section{Knowledge management in project environments}

For the purpose of this study a project environment is viewed as any environment or organisation where projects form a significant part of the business of the organisation. Nicholas (2001:22) describes a project as a temporary activity, performed by a multi-disciplinary team, working towards a single definable goal, while Koskinen, Pihlanto and Vanharanta (2003) propose that projects be viewed as an organisation of people dedicated to achieving a specific objective.
The perception that knowledge is a source of wealth and competitive advantage stimulates interest in knowledge management within project-based organisations (Fernie, Green, Weller \& Newcombe, 2003; Bresnen, Edelman, Newell, Scarbrough \& Swan, 2003). Project performance can be improved through shared best practices and appropriate, real-time information sharing (Durbin \& Wheeler, 2002). Lessons learned during the life-cycle of a project may prevent the repetition of errors in the same project or another, similar project and can thus reduce the costs and time for rework (Carrillo, Robinson, Al-Ghassani \& Anumba, 2004). The systematic documentation of mistakes or potential pitfalls helps to reduce project risk (Schindler \& Eppler, 2003), while customer satisfaction can be improved by consolidating customer information (Durbin \& Wheeler, 2002). Good ideas generated on a project should also be transferred to future projects.

Knowledge management in project environments involves the creation, administration, dissemination and utilisation of knowledge within and outside the project (Bresnen et al., 2003). Projects always produce project knowledge, including technical, procedural and organisational knowledge (Kasvi, Vartiainen \& Hailikari, 2003). Thus the challenge of knowledge management in project environments is the documentation and administration, as well as the distribution and sharing of newly generated knowledge.

The very nature of projects implies limited time and resources, multi-disciplinary processes and changing teams. This poses specific problems with regard to knowledge management. Members of project teams are often fully occupied with pressing project tasks, to the extent that they may not find the time to write detailed reviews (Purvis \& McCray, 2003) or to participate in knowledge sharing activities (Carrillo et al., 2004). Project knowledge is thus not captured or shared and will, together with the people involved in the project, dissipate when the project is terminated (Kasvi et al., 2003).

While explicit knowledge could be captured in project documentation such as schedules and technical reports, tacit knowledge (experiences, best practices) is difficult to capture in documentation (Schindler et al., 2003). Tacit knowledge is best transferred directly between people, but efficient transfer depends on building relationships, involving trust and lengthy timeframes (Fernie et al., 2003). People generally find it difficult to build trust in a limited time span (Nicholas, 2001:506), so that at the end of a project, the trust necessary for efficient transfer of tacit knowledge might still not exist.

The members of a project team could be dispersed both organisationally and geographically, (Kasvi et al., 2003), necessitating impersonal communication like electronic mail. Too much detail, confidentiality and idiosyncrasies of messages would often hinder effective communication. These people would also forfeit opportunities for interaction with other team members, making the transfer of tacit knowledge between team members difficult (Koskinen et al., 2003). Knowledge transfer in multi-disciplinary teams is especially challenging. These teams may consist of a range 
of professionals and artisans (Carrillo et al., 2004), utilising different processes and practices (Nicholas, 2001:13) and even speaking several languages (Kasvi et al., 2003).

Published research results emphasise that the main focus of knowledge management in project environments is on managing explicit knowledge (Fernie et al., 2003; Bresnen et al., 2003; Schindler et al., 2003). The PMBOK Guide (Project Management Institute, 2004:230) emphasises the distribution and retrieval of information. The codification of tacit knowledge is attempted by using review packages (Liebowitz \& Megbolugbe, 2003), project debriefings (Schindler et al., 2003), administrative closure procedures (Project Management Institute, 2004:101) and other knowledge repositories (Koskinen et al., 2003). It is, however, generally accepted that tacit knowledge is best gained and exchanged through social interaction which can take the form of participative workshops, debate and discussions (Fernie et al., 2003), informal face-to-face interaction (Koskinen et al., 2003), shadowing and mentoring (Liebowitz et al., 2003) and brainstorming sessions (Carrillo et al., 2004). While the culture of a company should support knowledge sharing (Liebowitz et al., 2003), the involvement of top management in creating a culture conducive to knowledge sharing is vital (Cleland, 1988). According to Carrillo et al. (2004), establishing a post with responsibility for knowledge management in project environments is essential. Schindler et al. (2003) defines the role of a 'project debriefer' who prepares and facilitates review workshops and who is responsible for the documentation of workshop results.

Several authors comment on the benefits of managing knowledge, not only within a single project (intra-project), but especially across projects (inter-project). Such interproject knowledge management could increase both competitiveness and profitability (Carrillo et al., 2004), and the systematic retention of project experiences could enable a company to compare various projects systematically and to focus on the most effective problem solving mechanisms (Schindler et al., 2003). Kasvi et al. (2003) propose a possible approach to inter-project knowledge management, while Bresnen et al. (2003) emphasise the difficulty experienced in integrating cross-functional contributions and perspectives.

\section{Framework for Knowledge Management in project environments}

From the literature review a framework for knowledge management in project environments was developed. Although the essential activities for the management of knowledge include the creation, codification, dissemination and the utilisation of knowledge, the creation and utilisation of knowledge fall outside the scope of the present study and are mentioned for purposes of completeness only. No details pertaining to these processes are entertained.

The proposed framework takes characteristics (mechanisms, challenges, processes and procedures) of knowledge management as point of reference and matches these to characteristics of project environments.
The Framework for Knowledge Management in project environments is presented in Diagram 1.

Some characteristics of project environments conform with (or could enhance) those of knowledge management, so that knowledge is (in these respects) automatically managed in project environments. These overlapping characteristics (indicated in italics in the framework) include:

- Documents/repositories are produced using standard work procedures (Bresnen et al., 2003; Schindler et al., 2003);

- A single person (the project manager) is responsible for convening meetings, workshops etc. for review/problem-solving purposes (Nicholas, 2001:478);

- Explicit knowledge, as well as tacit knowledge (lessons learned, best practices), is documented (codified) as minutes of meetings during the project life cycle, as well as at project close-out (Schindler et al., 2003; Kasvi et al., 2003).

Assuming that project management as a discipline is practised conscientiously, these aspects of knowledge management are to an extent addressed automatically within a project environment.

However, some characteristics of project environments deviate from those of knowledge management so that (in these respects) special attention should be given to managing knowledge in project environments. These challenging characteristics (indicated in bold in the framework) include:

- $\quad$ Project teams could consist of members from different disciplines and from various physical and cultural contexts (Kasvi et al., 2003; Carrillo et al., 2004);

- Trust is needed for the efficient transfer of knowledge among people. During the limited duration of a project, people often do not get familiar enough with one another to develop this trust (Bresnen et al., 2003; Koskinen et al., 2003);

- $\quad$ Projects are characterised by tight schedules, leaving people without the opportunity to participate in knowledge-sharing activities such as discussions and social interaction (Kasvi et al., 2003; Purvis et al., 2003).

The dissemination of tacit knowledge seems to be at a strong disadvantage in project environments, while codification of both explicit and tacit knowledge is automatically part of practising project management as a discipline. These conclusions from the literature would form the basis of the questions put to interviewees during this research. 


\begin{tabular}{|c|c|c|c|c|}
\hline Creation & \multicolumn{2}{|c|}{ Codification } & Dissemination & Utilisation \\
\hline & Explicit knowledge & Tacit knowledge & Explicit knowledge & Tacit knowledge \\
\hline Mechanisms & $\begin{array}{l}\text { Documents and } \\
\text { Repositories }\end{array}$ & $\begin{array}{l}\text { Documents and } \\
\text { Repositories }\end{array}$ & $\begin{array}{l}\text { Documents and IT- } \\
\text { systems }\end{array}$ & Human interaction \\
\hline Challenges & $\begin{array}{l}\text { - } \text { Standard work } \\
\text { processes } \\
\text { - } \text { Retrievable } \\
\text { 'packaging' e.g. key } \\
\text { words } \\
\text { - Skills to create } \\
\text { database and make } \\
\text { accessible } \\
\end{array}$ & $\begin{array}{l}\text { Difficult to extract } \\
\text { tacit knowledge from } \\
\text { a person } \\
\text { - Difficult to codify } \\
\text { meaning and context }\end{array}$ & $\begin{array}{l}\text { - Motivation of people } \\
\text { to contribute to the } \\
\text { database and use it } \\
\text { - Poor transfer due to } \\
\text { dispersed staff; } \\
\text { security; } \\
\text { confidentiality }\end{array}$ & $\begin{array}{l}\text { Dispersed teams } \\
\text { - Trust needed } \\
\text { between people } \\
\text { - 'Knowledge is power' } \\
\text { perception } \\
\text { - Time constraints } \\
\text { - People need to 'speak } \\
\text { the same language' } \\
\end{array}$ \\
\hline $\begin{array}{l}\text { Processes and } \\
\text { Procedures }\end{array}$ & $\begin{array}{l}\text { - Single responsible } \\
\text { person } \\
\text { - 'Librarian' }\end{array}$ & $\begin{array}{l}\text { - Meetings } \\
\text { - Workshops } \\
\text { - Responsible person }\end{array}$ & $\begin{array}{l}\text { Performance } \\
\text { appraisals } \\
\text { - Effort to enhance } \\
\text { communication, e.g. } \\
\text { video-conferences }\end{array}$ & $\begin{array}{ll}\text { - } & \text { Informal interaction } \\
\text { (co-location) } \\
\text { - } & \text { Longer tenure } \\
\text { - } & \text { Induction or team } \\
\text { building } \\
\text { - } \text { Mentorship } \\
\text { - } \text { Communities of } \\
\text { - } \text { practice } \\
\text { - } \text { Performance } \\
\text { - } \text { Jobpraisals } \\
\end{array}$ \\
\hline
\end{tabular}

Key: $\quad$ Italics $\quad$ Project management overlaps with knowledge management

Boldface Areas of concern in project management

\section{Diagram 1: Framework for knowledge management}

\section{Research goals}

While the literature on knowledge management in project environments is still sparse, published studies have been conducted elsewhere in the world, and no indication could be found pertaining to practices in any South African project environments. The primary objective of this study was therefore to investigate current knowledge management practices in a number of dissimilar cases within a single South African project environment.

Furthermore, research into practical ways to manage knowledge, both within a project and between projects seems incomplete at best. Conclusions from the literature (see framework for knowledge management in project environments in 1.3) indicate that the dissemination of tacit knowledge is especially challenging. Thus a further objective of this study was to propose a model for the management of knowledge within a single project (intraproject) as well as between projects (inter-project) with special attention to the dissemination of tacit knowledge.

\section{Research methodology}

For this research a case study approach was selected. The advantage of a case study is that this method allows investigators to study real-life events such as organisational and managerial processes and life cycles while retaining the holistic and meaningful characteristics of these events (Yin, 2003:2). A further, unique strength of the case study is its ability to deal with a full variety of evidence, e.g. documents, artefacts, interviews and observations (Yin, 2003:8).
The empirical research for this study was conducted in different project environments within a single South African company, making this an embedded case study. An embedded case study occurs when, within a single case, attention is given to a subunit or subunits (Yin, 2003:43).

Although case studies provide little basis for scientific generalisation (Yin, 2003:10), the goal of a case study must be to generalise theories by using analytic generalisation and not to enumerate frequencies (using statistical generalisation). In analytical generalisation, a previously developed theory is used as a template with which to compare the empirical results of the study (Yin, 2003:32). Considering this point of view, this study provides valuable information about knowledge management in project environments and also offers a starting point for future research.

This company is a commercial bank with operations right across South Africa. The selection of the target organisation was based on the following considerations:

- Project management is applied to achieve strategic changes, to optimise operations, to comply with regulatory requirements and to improve cost efficiency. An annual project budget exceeding R1billion is proof of the bank's commitment to project management. Project staff is also actively encouraged to study project management as a discipline.

- A variety of projects form part of the total project portfolio. Together with the different business units and support functions which represents different 
project environments, this organisation makes for a rich research subject.

- $\quad$ The bank has been in business for more than a decade and is highly profitable.

- $\quad$ An adequate level of access could be achieved so that data could be collected from different environments.

- The bank has furthermore adopted knowledge management as a strategic value.

In a recent audit, KPMG reported that the bank's approach to projects is well structured and concise. This was confirmed when AT Kearney consultants assessed the bank's project methodology as being well developed and certainly of world class. The level of project management practised in this company therefore ensured that this environment was a worthy subject for research.

\section{Cases $A, B$ and $C$}

Three different project environments within the same South African company have been selected.

Case A: This environment is the centre of company-wide project management and employs only fulltime project staff, including project managers and programme managers. The staff manage large-scale projects and other strategically important projects with team members across the entire company. Case A provided the opportunity to study knowledge management within projects with large, changing and dispersed project teams (intra-project), as well as the sharing and transfer of knowledge between projects (inter-project).

Case B: This environment is a highly successful business unit with its own line function and with dedicated project staff. Project managers in Case B manage the internal projects of the business unit or act as project leaders for subprojects of large projects.

Case C: The unit under consideration delivers a vital input into all business operations throughout the bank. About 80\% of projects managed by these project managers are subprojects of company-wide projects, executed by dedicated project staff in a stable environment.

Cases B and C provided the opportunity to study the sharing and transfer of knowledge within small, stable project teams (intra-project).

Characteristics of Cases A, B and C are summarised as follows:

Table 1: Profiles of Cases A, B and C

\begin{tabular}{l|l|l|l}
\hline & \multicolumn{1}{|c|}{$\begin{array}{c}\text { Case A } \\
\text { intra-project }\end{array}$} & \multicolumn{1}{c}{$\begin{array}{c}\text { Case A } \\
\text { inter-project }\end{array}$} & $\begin{array}{c}\text { Case C } \\
\text { intra-project } \\
\text { intra-project }\end{array}$ \\
\hline $\begin{array}{l}\text { Size of typical project } \\
\text { team }\end{array}$ & $\begin{array}{l}\text { core team: } 10 \\
\text { extended team: up to } 100\end{array}$ & not applicable & 2 to 5 people \\
\hline Participants & multi-disciplinary teams & project managers & multi-disciplinary teams \\
\hline $\begin{array}{l}\text { Location of } \\
\text { Participants }\end{array}$ & $\begin{array}{l}\text { dispersed across towns/ } \\
\text { buildings }\end{array}$ & co-located \\
\hline Physical environment & $\begin{array}{l}\text { venues for meetings vary: } \\
\text { no 'war rooms' }\end{array}$ & $\begin{array}{l}\text { cramped communal } \\
\text { spaces }\end{array}$ & $\begin{array}{l}\text { spacious; permanent venues } \\
\text { for meetings }\end{array}$ \\
\hline Tenure & $\begin{array}{l}\text { limited to project life cycle } \\
\text { venucious; permanent for meetings } \\
\text { staff }\end{array}$ & $\begin{array}{l}\text { working together for a few } \\
\text { years }\end{array}$ \\
\hline
\end{tabular}

It should be noted that the case study methodology limits the generalisability of results. Participants in this study and the project environments studied were selected for good reason, but the choice could not be described as random. The number of cases and the number of participants were also limited and were from similar cultural backgrounds.

\section{Interviews}

For this study, semi-structured interviews were used. In all, 13 project participants were interviewed. The interviewees were selected to represent programme managers, project managers, project team members and staff from the project office. Interviews were conducted one-on-one or in small groups of two interviewees and lasted from 45 to 60 minutes each.

Open-ended questions were formulated from findings in the literature. Questions focused on tasks and roles of participants in projects; the size, location and composition of project teams; the mechanisms employed to manage knowledge; perceptions related to the impact of organisational culture and staff tenure on knowledge transfer; as well as the options available to obtain assistance when needed.

\section{Other sources of data}

As the quality of a case study is enhanced by the use of multiple sources of evidence (Yin, 2003:85), the following sources were used to verify data obtained from people interviewed:

- Documentation: obtained from the target organisation

- $\quad$ Direct observation: during field visits to the different sites 
- Participant-observation: while attending and participating in a training session at the study organisation.

\section{Results}

Knowledge management practices in a specific South African environment

Information Technology (IT) systems are used in all the studied environments to capture and store explicit knowledge such as budgets, schedules and minutes of meetings. No standard structure for project documentation exists, no 'packaging' of information or keywords for information retrieval are evident, so that it is perceived to be easier to obtain information from a colleague than from the database. No single person is responsible for knowledge management. Individual project managers may accept responsibility for the information on the IT-system and for the dissemination thereof to their project teams, but no formal procedures exist.

Although formal induction programmes for new staff members exist in some of the studied environments, teambuilding activities at the start of a project is not regarded as a high priority. To start working on the new project seems to be more urgent.

For practical reasons (e.g. to save on time and on the expense of travelling) status meetings for more dispersed project teams in Case A are less frequently scheduled.

The lack of informal interaction observed in the studied environments, is ascribed to limitations in the physical environments (see Table 1) as well as to pressing time lines and heavy workloads. Social interaction (where encountered) is limited because of time restrictions and increasing diversity of project teams: ladies seem to be in a hurry to get home, preferences for social activities vary with cultural diversity, etc.

Findings from the research are summarised below.

The culture of knowledge sharing differs significantly between the environments studied. The main factors influencing a positive culture for the sharing and transfer of knowledge seem to be: (1) physical environment: co-located teams, in an environment conducive to informal interaction, share and transfer knowledge more readily; (2) tenure of project staff: where people have been working together for a considerable time, they know and trust one another and therefore share and transfer knowledge more easily; (3) size of project teams: smaller teams are more likely to get acquainted and to share knowledge. The utilisation of procedures such as induction and mentorship also affects the culture of knowledge sharing.

The management of knowledge: intra-project and inter-project

Intra-project knowledge management. Explicit knowledge is codified by producing minutes of regular meetings and other project documentation. Information is disseminated through paper documents and/or IT systems. Project managers take the responsibility for project documentation while some project managers also facilitate the dissemination thereof.

Management of tacit knowledge through human interaction is influenced by physical environment, location of team and tenure of team members. No appraisal for mentoring or knowledge sharing exists. The human interaction part of project management (team building, mentoring) is not consciously practised.

Inter-project knowledge management. Information about all projects is available on the intranet but no 'packaging' of lessons learned or best practices exists, so that the intranet is perceived to be difficult to use. No formal meetings across projects are evident. Although project managers are colocated, little informal interaction between them exists, mainly due to the constraints posed by their physical environment and tight schedules.

The culture for knowledge sharing between projects is perceived to be very negative: the general consensus is 'everybody for himself'. This is in part due to the great number of new project staff and to the lack of an induction process. The informal mentorship programme seems to be totally ineffective. The burden of knowledge sharing and transfer is too heavy on the few people familiar with the processes and procedures.

While in Case A (inter-project) the culture is not conducive to knowledge sharing and personal development, this could partly be responsible for the high attrition rate of project managers. The replacement of project managers is a difficult process, complicated by requirements to meet certain employment equity targets.

\section{Discussion}

\section{Knowledge management practices in a specific South African environment}

Although interviewees were aware of the benefits of knowledge management, it is not practised on a conscious level.

Management of explicit knowledge. The main focus in the studied South African environments was on information capturing and the limited dissemination thereof, using ITsystems or documentation. This corresponds with reported practices elsewhere.

In accordance with the findings of Bresnen et al. (2003), human factors were also found to influence the use of these technologies: people should be motivated to use databases effectively. No specific person is responsible for the management of knowledge, resulting in uncoordinated and unsystematic efforts. These un-standardised procedures were found to hamper the use of the IT system, confirming the findings of Kasvi et al. (2003) and of Carrillo et al. (2004). As these practices are not formally measured by performance appraisals, an opportunity exists to improve staff motivation. 
Management of tacit knowledge. Codification of tacit knowledge is attempted by conducting regular review meetings. These meetings are documented on a continuous basis while the project is still in progress, in accordance with suggestions by Schindler et al. (2003). The notion that tacit knowledge is rather difficult to acquire and to transfer was also encountered in the studied environments: people find it easier or preferable to get information from a colleague than to search for it elsewhere. This confirms the findings of Koskinen et al. (2003) and Kasvi et al. (2003).

The sharing of tacit knowledge through social interaction also followed patterns established elsewhere. Co-located teams (thus engaged in constant informal interaction) seemed more likely to share and transfer tacit knowledge. Smaller teams consisting of people who know and trust one another are beneficial for knowledge transfer. Longer tenure of project staff and efficient induction programmes for new team members, as well as the existence of a positive culture, were found to be contributing factors toward effective knowledge sharing and transfer.

Where teams were bigger and/or dispersed, informal interaction was difficult and this hampered the sharing and transfer of knowledge. A culture conducive for, and the trust necessary to enhance knowledge sharing, is not developed without conscious effort.

The findings of this study confirm published results and indicate that human interaction is crucial for the sharing and transfer of especially tacit knowledge. This interaction can take a variety of forms, many of which are already adhered to in project environments, such as regular meetings and distributed documentation.

\section{Intra-project and inter-project knowledge management}

Knowledge management within a single project (intraproject). Findings indicated that, while project management principles were closely adhered to, knowledge was, to an extent, automatically managed within projects. Project management practices including meetings, workshops, documentation and distribution of information already constitute knowledge management, addressing the codification strategy.

The sharing and transfer of tacit knowledge (the personalisation strategy) remains a problem. This could be ascribed to the limited interaction among project team members. Team building, induction and mentorship programmes and informal social interaction, while supposed to be part of the project management discipline, do not always realise in practice and could be enhanced. This would allow for the members of a project team to get acquainted with one another and for trust to develop among them. This would make the sharing and transfer of knowledge (especially tacit knowledge) a more viable possibility.

Knowledge management across different projects (interproject). Findings indicate that different projects are managed as separate entities and little contact exists between different project managers or different project teams. While in other organisations knowledge dissemination could be enhanced by rotating staff between various business units, in a project organisation the project managers are automatically 'rotated' between projects. Although information pertaining to other projects is available, no conscious effort is made to manage the accumulated knowledge of these project managers, thus no codification strategy exists. Limited human interaction between project managers hampers the formation of trust, resulting in a negative culture and high attrition rate. While the replacement of project managers is problematic, the personalisation strategy of knowledge management should be enhanced. This would include recognising project managers as knowledge workers and creating an environment in which project managers could share their knowledge and experience, contribute to organisational learning and develop personally.

\section{Proposed model for knowledge management in project environments}

The model is proposed on two levels: within a single project (intra-project) and between projects (inter-project). The proposed model expands the model of Kasvi et al. (2003) in assigning the responsibility for knowledge management to a specific person and in identifying procedures that could enhance knowledge management in project environments. The two strategies of codification and personalisation of knowledge (Hansen et al., 1999) are used and the model of Schindler et al. (2003) is incorporated in that the knowledge management process is seen as a continuous process rather than as restricted to project close-out.

Management of knowledge within a specific project. A specific person should be responsible for the management of knowledge within a project. As an integral part of his project management duties, the project manager already manages the preparation and systematic distribution of documentation (codification). The project manager is also responsible for communication and other interaction within his project team (personalisation). Although informal social interaction seldom forms part of the project plan, some project managers would spontaneously engage their teams in such activities, while other project managers should be encouraged to do so through guidance or even formal, prescribed procedures. It thus seems that the project manager is the natural point of responsibility for knowledge management within a project team.

A few adaptations to general practice might, however, be necessary to make this suggestion viable. This would include top management involvement that could include: funds (if needed) for social and other interaction like colloquiums, but especially the relaxation of schedules to allow time for knowledge management activities. While this would initially delay projects, the authors are of the opinion that this disadvantage would be overshadowed by the benefits gained. The payback period would be acceptable. The project manager would also need administrative help to codify and systematically store and retrieve knowledge. Help with the organising of human interaction on different levels could also resort with this person. Procedures such as 
teambuilding and initiation of new project team members could be utilised, while more attention should be paid to human interaction on both formal and informal levels. Performance appraisals should be expanded to include participation in knowledge management activities so that team members would be motivated to share and transfer knowledge.

Knowledge management between projects. In project organisations it could well be true that several project managers are employed simultaneously. Such project managers can safely be assumed to collectively have accumulated much experience and tacit knowledge concerning projects in general and their own specific environments in particular. Project managers must therefore be recognised as knowledge workers and be managed as such.

In addition to a specific person being responsible for knowledge management within a project, a specific person should also be responsible for the management of knowledge between projects. Such a knowledge manager should institute procedures such as the initiation of new project managers, mentoring programmes (facilitating socialising and career development of new recruits), regular review meetings between project managers (codifying explicit knowledge and tacit knowledge to a degree) and informal social interaction. In this way, communities of practice could develop between project managers, allowing for stimulation and the transfer of tacit knowledge. The knowledge manager should be appointed in the project office, with the responsibility to act as administrator and to codify and personalise the knowledge of project managers. Performance appraisals should recognise the contribution of project managers toward knowledge management.

The proposed flow of knowledge in project environments, within a single project (intra-project) and between projects (inter-project) can be represented as follows:

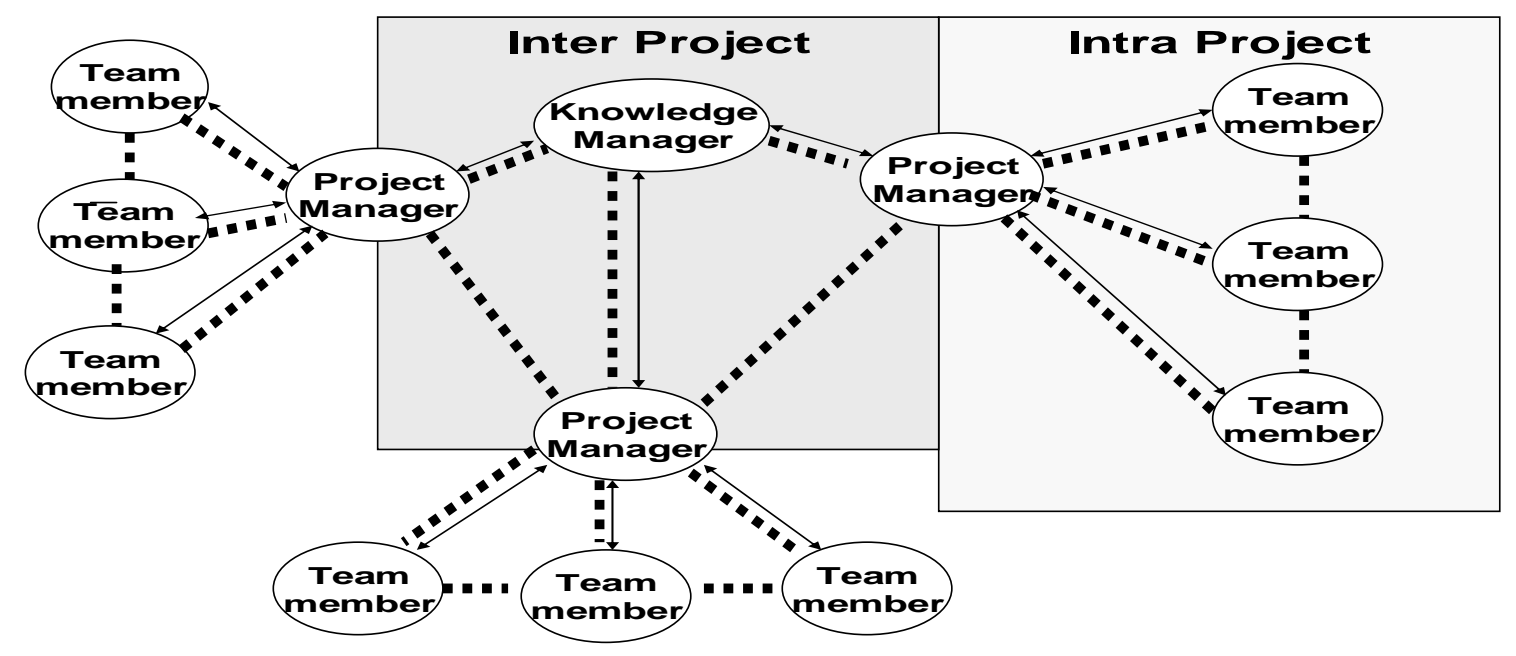

Key:

_ formal interaction (flow of explicit and codified tacit knowledge)

- . - . informal interaction (sharing of especially tacit knowledge)

\section{Diagram 2: Proposed model for knowledge management in project environments}

\section{Conclusions}

Knowledge management practices in the South African environment. The findings of this study, conducted in a specific project environment in South Africa, confirm the results of studies performed elsewhere in the world. The results conclude that the main focus of knowledge management remains the capturing and dissemination of information using Information Technology systems. Limited attention is given to the transfer and sharing of knowledge through human interaction on different levels. While the application of project management principles already prescribes certain actions geared toward knowledge management, the enhancement of human interaction could significantly improve the management especially that of tacit knowledge.

Intra-project knowledge management. The codification and dissemination of intra-project knowledge is addressed by applying project management practices such as regular meetings with minutes distributed afterwards. The strategy of personalising knowledge deserves more attention: tacit knowledge is best transferred between people during direct interaction. Procedures such as teambuilding and induction or mentorship programmes already form part of project management practices and should be enhanced to facilitate knowledge management.

A specific person should be made responsible for the management of knowledge in an individual project. While the project manager already manages documentation, communication and distribution of information within his project team, it stands to reason that knowledge management should be added to his or her responsibilities. A few minor adaptations to general practice are, however, necessary.

Inter-project knowledge management. Different projects in a project organisation tend to be managed as separate entities so that little transfer of knowledge between projects 
exists. The accumulated experience and knowledge of project managers should be shared and transferred between projects for the benefit of the whole organisation.

A specific person should be made responsible for the codification as well as the personalisation of the knowledge of project managers. Regular meetings and other informal interaction between project managers should be organised to achieve this goal. Procedures such as induction and mentoring programmes should be encouraged to enhance the sharing and transfer of knowledge between project managers.

\section{Further research}

Although this research was restricted to a single South African company, multiple project environments were studied and the findings of other studies were confirmed. Many authors agree about the need for further research in knowledge management, specifically in project environments. Although results from this study do not provide the final answer, it provides a basis for further investigation into the dissemination of tacit knowledge in project environments. It is suggested that more research is needed into the proposed model for knowledge management in project environments and especially the practical application thereof. The role of the project manager within various project structures e.g. matrix, projectised team and functional structures regarding knowledge management should also be investigated and clarified.

\section{References}

Allee, V. 2003. The future of knowledge. Burlington: Elsevier Science.

Bowman, B. J. 2002. 'Building knowledge management systems’, Information Systems Management, 9:32-40.

Bresnen, M., Edelman, L., Newell, S., Scarbrough, H. \& Swan, J. 2003. 'Social practices and the management of knowledge in project environments', International Journal of Project Management, 21:157-166.

Carrillo, P., Robinson, H., Al-Ghassani, A. \& Anumba, C. 2004. 'Knowledge management in UK construction: Strategies, resources and barriers', Project Management Journal, 35:46-56.

Cleland, D. I. 1988. 'The cultural ambience of project management - another look', Project Management Journal, XIX(3).

Davenport, T.H., Jarvenpaa, S.L. \& Beers, M.C. 1996. 'Improving knowledge work processes', Sloan Management Review, Summer:53-64.

Durbin, P. \& Wheeler, W. 2002. 'The core of centralized management: Integrating project management with other business processes', Planview [online] http://www.planview.com. Accessed 12 April 2004.
Fernie, S., Green, S.D., Weller, S. J. \& Newcombe, R. 2003. 'Knowledge sharing: Context, confusion and controversy', International Journal of Project Management, 21: 177-187.

Garvin, D.A. 1993. 'Building a learning organization', Harvard Business Review, July-August: 78-91.

Griffith, T. L., Sawyer, J. E. \& Neale, M.A. 2003. 'Virtualness and knowledge in teams: Managing the love triangle of organizations, individuals and information technology', MIS Quarterly, 27:265-287.

Hansen M. T., Nohria N. \& Tierney T. 1999. 'What's your strategy for managing knowledge?', Harvard Business Review, March-April:106-116.

Kasvi, J. J. J., Vartiainen, M. \& Hailikari, M. 2003. 'Managing knowledge and knowledge competences in projects and project organisations', International Journal of Project Management, 21:571-582.

King, W.R. 2001. 'Strategies for creating a learning organisation', Information Systems Management, 18:12-20.

Koskinen, K. U., Pihlanto, P. \& Vanharanta, H. 2003. 'Tacit knowledge acquisition and sharing in a project work context', International Journal of Project Management, 21: 281-290.

Liebowitz, J. \& Megbolugbe, I. 2003. 'A set of frameworks to aid the project manager in conceptualising and implementing knowledge management initiatives', International Journal of Project Management, 21: 189-198.

Nicholas, J. M. 2001. Project management for business and technology, 2nd Edition. Upper Saddle River, New Jersey: Prentice Hall.

Nevis, E. C., DiBella, A. J. \& Gould, J. M. 1995. 'Understanding organizations as learning systems', Sloan Management Review, Winter: 73-85.

Nonaka, I., Toyama, R. \& Konno, N. 2001. 'SECI, Ba and leadership: A unified model of dynamic knowledge creation'. In Nonaka, I. \& Teece, D. (Eds.). Managing industrial knowledge. London: Sage Publications.

Project Management Institute. Standards Committee. 2004. A guide to the project management body of knowledge (PMBOK). Newtown Square, Pennsylvania: Project Management Institute.

Purvis, R. L. \& McCray, G. E. 2003. 'Project assessment: A tool for improving project management', Information Systems Management, April/May:55-60.

Schindler. M. \& Eppler, M. J. 2003. 'Harvesting project knowledge: a review of project learning methods and success factors', International Journal of Project Management, 21:219-228.

Spiegler, I. 2003. 'Technology and knowledge: bridging a 'generating' gap', Information \& Management, 40:533-539. 
Stata, R. 1989. 'Organizational learning - the key to management innovation', Sloan Management Review, Spring: 63-74.

Stewart, T. A. 2001. The wealth of knowledge. London: Nicholas Brealey Publishing.

Whysall, P. 2003. 'Winning the knowledge race. Meeting the HR challenge in South Africa,' HR Future, June:10-11.

Yin, R. K. 2003. Case study research design and methods, 3rd Edition. Thousand Oaks, California: Sage Publications. 